\title{
Role of Calcineurin in Nicotine-Mediated Locomotor Sensitization
}

\author{
Nii A. Addy, ${ }^{1,2}$ Eugenio F. Fornasiero, ${ }^{2}$ Tanya R. Stevens, ${ }^{2}$ Jane R. Taylor, ${ }^{1,2}$ and Marina R. Picciotto ${ }^{1,2}$ \\ ${ }^{1}$ Interdepartmental Neuroscience Program and ${ }^{2}$ Department of Psychiatry, Yale University School of Medicine, New Haven, Connecticut 06508
}

\begin{abstract}
Calcineurin is a serine/threonine phosphatase that contributes to the effects of nicotine on calcium signaling in cultured cortical neurons; however, the role of calcineurin in behavioral responses to nicotine in vivo has not been examined. We therefore determined whether calcineurin blockade could alter nicotine-mediated locomotor sensitization in Sprague Dawley rats using systemic or brain regionspecific administration of the calcineurin inhibitors cyclosporine or FK506. Systemic cyclosporine administration decreased calcineurin activity in the brain, attenuated nicotine-mediated locomotor sensitization, and blocked the effects of nicotine on DARPP32 (dopamineand cAMP-regulated phosphoprotein-32) activation in the striatum. Direct infusion of calcineurin inhibitors cyclosporine or FK506 into the ventral tegmental area (VTA) also attenuated nicotine-mediated locomotor sensitization, whereas infusion of rapamycin, which binds to FK-binding protein but does not inhibit calcineurin, did not affect sensitization. Together, the data suggest that activation of calcineurin, particularly in the VTA, is a novel signaling event important for nicotine-mediated behavior and intracellular signaling.
\end{abstract}

Key words: nicotine; calcineurin; locomotor activity; sensitization; ventral tegmental area; DARPP32

\section{Introduction}

Recent estimates indicate that there are 46.2 million smokers in the United States alone, with smoking-related deaths numbering $>440,000$ each year (Centers for Disease Control and Prevention, 2006). Nicotine, which is the primary reinforcing agent in tobacco, activates nicotinic acetylcholine receptors (nAChRs) that are located throughout the brain (McGehee and Role, 1995; Picciotto, 1998; Laviolette and Van der Kooy, 2004). Specifically, the effects of nicotine in the mesolimbic dopamine system, consisting of dopamine projections from the ventral tegmental area (VTA) to nucleus accumbens (NAc), are thought to contribute to the behavioral changes associated with nicotine administration (Kita et al., 1992; Panagis et al., 1996; Mansvelder et al., 2002; Laviolette and Van der Kooy, 2004). Nicotine-induced plasticity within the VTA itself has been clearly demonstrated (Fu et al., 2000; Mansvelder et al., 2002; Saal et al., 2003; Laviolette and Van der Kooy, 2004), and the VTA is known to play a critical role in nicotine-mediated behaviors (Corrigall et al., 1994; Ferrari et al., 2002) that likely contribute to nicotine craving in humans.

Within the VTA, however, there is a need for a greater understanding of the role of effector proteins important for both nicotine-mediated plasticity and behavior. One protein that may play an important role in the VTA is calcineurin, a serine/threonine phosphatase that has been shown to mediate nicotinic ef-

Received March 5, 2007; revised June 29, 2007; accepted June 29, 2007.

This work was supported by Grants DA14241 and AA15632 from the National Institutes of Health. N.A.A. was supported by Grant MH18882 from the American Psychological Association and Grant DA021459 from the National Institutes of Health. M.R.P. was supported by Grant DA00436, and J.R.T. was supported by Grant DA11717, both from the National Institutes of Health.

Correspondence should be addressed to Dr. Marina R. Picciotto, 34 Park Street, 3rd Floor Research, New Haven, CT 06508. E-mail: marina.picciotto@yale.edu.

DOI:10.1523/JNEUROSCI.2601-07.2007

Copyright $\odot 2007$ Society for Neuroscience $\quad$ 0270-6474/07/278571-10\$15.00/0 fects on calcium dynamics in cultured cortical neurons (Stevens et al., 2003). Calcineurin, when activated, dephosphorylates target proteins including calcium channels, AMPA receptors, NMDA receptors, synapsin I, the dopamine- and cAMPregulated phosphoprotein-32 (DARPP32), and the cAMP response element-binding protein (CREB) (Greengard et al., 1999; Jovanovic et al., 2001; Winder and Sweatt, 2001), all of which can modulate plasticity. The involvement of calcineurin in hippocampal plasticity has been clearly demonstrated. Calcineurin activity modulates both glutamatergic and GABAergic tone (Yakel, 1997; Groth et al., 2003) as well as long-term potentiation, long-term depression (LTD), and learning (Lisman, 1989; Lu et al., 2000; Wang et al., 2003; Lee and Ahnn, 2004). In these studies, we address the hypothesis that calcineurin activity modulates VTA plasticity as well. Given the critical role of the VTA in nicotine-mediated plasticity and behavior, along with the ability of calcineurin to alter synaptic plasticity, we examined the contribution of calcineurin to locomotor sensitization, a nicotinemediated behavior that is thought to result from plasticity in the VTA (Kita et al., 1992; Panagis et al., 1996). We also examined the effect of calcineurin blockade on intracellular signaling downstream of nAChR activation to further elucidate the underlying mechanisms of the effects of nicotine on behavior. Our results demonstrate that calcineurin activity contributes to the behavioral responses to repeated nicotine administration and to downstream intracellular signaling, and suggest a novel role for calcineurin activity in the VTA for nicotine-mediated plasticity.

\section{Materials and Methods}

Subjects. Male Sprague Dawley rats weighing between 200 and $250 \mathrm{~g}$ on arrival were obtained from Charles River Laboratories (Wilmington, MA). Animals were placed on ad libitum food and water and were housed two to three per cage on a $12 \mathrm{~h}$ light/dark cycle with lights on at 7:00 A.M. 
All experiments were conducted according to the Guide for the Care and Use of Laboratory Animals and were approved by the Yale University Animal Care and Use Committee.

Locomotor activity. Locomotor activity was assessed using Micro Pro software (version 1.3; Omnitech Electronics, Dartmouth, Nova Scotia, Canada) and was quantified by infrared beam breaks. During each session, animals received a 30 min habituation period in the testing cage, followed by a subcutaneous injection and subsequent assessment of locomotor activity for up to $60 \mathrm{~min}$.

Drug administration. Repeated oral administration of cyclosporine (15 $\mathrm{mg} / \mathrm{kg}$ ) has been demonstrated to increase plasma cyclosporine levels in rats (Donatsch and Ryffel, 1986). Furthermore, cyclosporine administration at a higher dose $(50 \mathrm{mg} / \mathrm{kg})$ led to greater plasma cyclosporine levels when administered by intraperitoneal injection compared with oral administration (Donatsch and Ryffel, 1986). Thus, for systemic administration studies, animals received daily intraperitoneal injections of 15 $\mathrm{mg} / \mathrm{kg}$ cyclosporine (Sandimmune Oral Solution; Novartis, East Hanover, NJ) or olive oil vehicle (ICN Biochemicals, Cleveland, OH) in combination with a subcutaneous injection of $0.35 \mathrm{mg} / \mathrm{kg}$ free base nicotine ( $\mathrm{pH}$ set to 7 with $\mathrm{NaHCO}_{3}$; Sigma-Aldrich, St. Louis, $\mathrm{MO}$ ) or saline vehicle ( $0.9 \%$ sodium chloride; Hospira, Lake Forest, IL). All drugs were injected in a volume of $2 \mathrm{ml} / \mathrm{kg}$ body weight. Cyclosporine or olive oil vehicle was injected $1 \mathrm{~h}$ before the habituation period, and nicotine or saline was injected immediately after the $30 \mathrm{~min}$ habituation period. For intracranial infusion, cyclosporine (Sandimmune Injection; Novartis) dissolved in PBS (Invitrogen, Carlsbad, CA), FK506 (Sigma-Aldrich) dissolved in dimethylsulfoxide (DMSO; Sigma-Aldrich), rapamycin (Biomol, Plymouth Meeting, PA) dissolved in $75 \%$ Tween 20 and $25 \%$ DMSO (Sigma-Aldrich), or vehicle was bilaterally infused at a dose of 1 $\mu \mathrm{g}$ per side per day at the rate of $0.25 \mu \mathrm{l} / \mathrm{h}$ with an Alzet osmotic minipump (model 2004; Durect Corporation, Cupertino, CA). The vehicle drug in the cyclosporine experiments consisted of 30\% EtOH/70\% Cremaphor (Sigma-Aldrich) added to PBS at a volume equal to that of Sandimmune Injection added to PBS for cyclosporine infusion. In the FK506 study, vehicle consisted of DMSO added to PBS at a volume equal to that of FK506 added to PBS for FK506 infusion. In the rapamycin study, vehicle consisted of 75\% Tween 20/25\% DMSO added to PBS at a volume equal to that of rapamycin added to PBS for the infusion.

Surgical procedure. Before drug infusion, surgery was performed to implant intracranial cannulas directed at either the VTA or NAc for chronic drug infusion. Animals were anesthetized with Equithesin injected at a volume of $4.32 \mathrm{ml} / \mathrm{kg}$. Subjects were then secured in a stereotaxic apparatus (David Kopf Instruments, Tujunga, CA) where surgery was performed under aseptic conditions. Bilateral cannulas (Plastics One, Roanoke, VA) were inserted and aimed at the VTA [anteroposterior $(\mathrm{A} / \mathrm{P}),-5.3 \mathrm{~mm}$; mediolateral $(\mathrm{M} / \mathrm{L}),-1.0 \mathrm{~mm}$; dorsoventral $(\mathrm{D} / \mathrm{V})$, $-7.0 \mathrm{~mm}$; bite bar, $0.0 \mathrm{~mm}$ ] or NAc (A/P, $-1.7 \mathrm{~mm}$; M/L, $-1.5 \mathrm{~mm}$; $\mathrm{D} / \mathrm{V},-6.0 \mathrm{~mm}$; bite bar, $-3.3 \mathrm{~mm}$ ). Before insertion, cannulas were connected, via polyethylene tubing (Plastics One), to an Alzet osmotic minipump containing cyclosporine, FK506, or vehicle (PBS) in the doses mentioned above. Animals were allowed to recover for 4-7 d before locomotor testing began.

Brain dissection and histology. At the completion of the behavioral studies, animals were killed by rapid decapitation $15 \mathrm{~min}$ after subcutaneous injection with nicotine or saline, and the entire head was immediately frozen in chilled 2-methyl butane (VWR International, West Chester, PA). Each brain was later removed and sliced into 1-2 $\mathrm{mm}$ sections using a chilled matrix (Zivic Labs, Pittsburgh, PA). Cannula placement in surgerized animals was visually assessed in brain tissue slices, and subjects with cannula placements outside of the target region were excluded from analysis. Region-specific dissections of prefrontal cortex (PFC), striatum, NAc, VTA, and hippocampus were performed using micropunch tools made from 16 or 18 gauge needles.

Western blot analysis. Tissue samples were prepared for Western blot analysis and run on a $10 \%$ polyacrylamide gel at a protein concentration of 5 or $10 \mu \mathrm{g}$ per sample, as described previously (Brunzell et al., 2003). Nitrocellulose blots were then briefly washed in Tris-buffered saline (TBS; $20 \mathrm{~mm}$ Tris base and $137 \mathrm{~mm} \mathrm{NaCl}$ adjusted to $\mathrm{pH} 7.6$ ) and blocked in TBS with $0.05 \%$ Tween 20 (Sigma-Aldrich) and 5\% skim milk. Mem- branes were then incubated overnight at $4^{\circ} \mathrm{C}$ with primary antibodies against the following proteins: calcineurin (1:1000; BD Biosciences, San Jose, CA), DARPP32 (1:1000; Cell Signaling, Danvers, MA), Synapsin I (1:1000; Cell Signaling), actin (1:4000; Sigma-Aldrich), glyceraldehyde3-phosphate dehydrogenase (GAPDH; 1:30,000; Advanced Immunochemical, Long Beach, CA), and pDARPP32 (Thr 34), pDARPP32 (Thr 75), pSynapsin I (Ser 62/Ser 67), or pSynapsin I (Ser 9) (1:500; all courtesy of A. Nairn, Yale University, New Haven, CT).

Blots were then briefly washed in TBS with $0.05 \%$ Tween, followed by a $1 \mathrm{~h}$ incubation at room temperature with one of the following secondary antibodies: anti-rabbit IgG (1:2000; Vector Laboratories, Burlingame, CA), anti-mouse IgG (1:2000; Vector Laboratories), anti-rabbit IgG Rockland IR Dye 780 (1:5000; Rockland Immunochemicals, Gilbertsville, PA), or anti-mouse IgG Alexa Fluor 680 (1:5000; Invitrogen). After incubation, blots were washed three times with TBS-Tween, immersed for $1 \mathrm{~min}$ in enhanced chemiluminescence reagents (Amersham Biosciences, Piscataway, NJ), and exposed and developed on X-OMAT AR or Biomax MR film (Eastman Kodak, Rochester, NY). Blots incubated with fluor antibodies (Rockland IR dye and Alexa Fluor) were not immersed in chemiluminescence reagents but were instead scanned using an Odyssey scanner (version 1.2; LI-COR Biosciences, Lincoln, NE). Protein bands were then analyzed and quantified using either NIH ImageJ software (http://rsb.info.nih.gov/ij/download.html) or Odyssey software (version 1.2; LI-COR Biosciences).

Data analysis. Locomotor activity was quantified by the total number of beam breaks during the testing session. The data were then analyzed by a repeated-measures ANOVA with testing day as the repeated measure, beginning on day 1 of treatment. If there was a significant interaction between testing day and drug treatment, we then performed a Tukey's post hoc test. Locomotor activity after an acute nicotine or saline challenge was compared with activity on the day before the challenge and assessed for significance using a univariate ANOVA. For Western blot analysis, band intensity for each protein was normalized to that of GAPDH or actin, which served as protein loading controls. In addition, all quantifications were normalized to control animals set at $100 \%$. Statistical significance was determined using a univariate ANOVA with a post hoc independent-samples $t$ test. For every statistical test presented here, significance was determined with a $p$ value of $\leq 0.05$. All statistical tests were performed using SPSS 12.0 software (SPSS, Chicago, IL).

\section{Results \\ Chronic systemic cyclosporine administration attenuates nicotine-mediated locomotor sensitization}

To determine whether calcineurin activity plays a role in nicotine-mediated locomotor sensitization, we observed locomotor activity during daily administration of nicotine $(0.35 \mathrm{mg} /$ $\mathrm{kg}$, s.c.) or saline in combination with cyclosporine (15 $\mathrm{mg} \cdot \mathrm{kg}^{-1} \cdot \mathrm{d}^{-1}$, i.p.) or vehicle (Fig. $1 \mathrm{~A}$ ). Peak locomotor activity was observed in the first $15 \mathrm{~min}$ after nicotine administration in each testing session (supplemental Fig. 1A, available at www. jneurosci.org as supplemental material); thus total activity in this $15 \mathrm{~min}$ bin was compared across treatment days (Fig. 1C). This analysis revealed a significant effect of treatment across testing days $\left(F_{(8,480)}=27.064 ; p<0.001\right)$ (Fig. $\left.1 C\right)$ along with a significant effect of drug treatment $\left(F_{(3,60)}=105.361 ; p<0.001\right)$ (Fig. 1C) and interaction between test day and drug treatment $\left(F_{(8,480)}=27.064 ; p<0.001\right)$ (Fig. $\left.1 C\right)$. Animals receiving daily nicotine administration showed a sensitized increase in locomotor activity compared with control animals $(p<0.001)$ (Fig. 1C). Furthermore, coadministration of the calcineurin inhibitor $\mathrm{cy}-$ closporine attenuated nicotine sensitization $(p<0.005)$ (Fig. $1 C)$, suggesting that calcineurin activity contributes to nicotinemediated locomotor sensitization, although it did not abolish the increase in nicotine-mediated locomotor activation (Fig. 1C). We also determined whether calcineurin was necessary for acute effects of nicotine by administering a nicotine challenge $(0.35$ 
A) Locomotor Paradigm

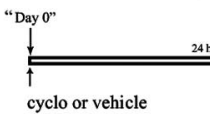
cyclo or vehicle
$(15 \mathrm{mg} / \mathrm{kg}$, i.p.)

B) Total Habituation Activity

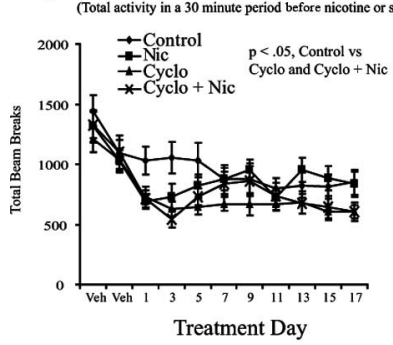

D) Acute Nicotine Challenge

(Total activity in a 15 minute period following nicotine or saline)

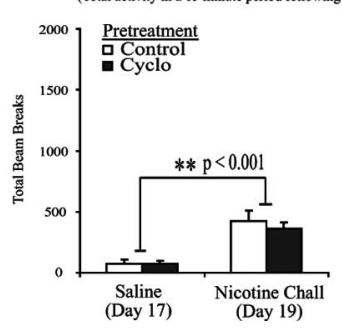

Figure 1. Chronic cyclosporine administration attenuates nicotine-induced locomotor sensitization. Repeated nicotine administration to Sprague Dawley rats ( $n=16$ per group) leads to locomotor sensitization that is attenuated by chronic systemic cyclosporine coadministration. $\boldsymbol{A}$, Locomotor testing paradigm and timeline. $\boldsymbol{B}$, Total activity during the 30 min habituation period across the $17 \mathrm{~d}$ treatment period. Statistical analysis revealed an effect of treatment $\left(F_{(3,60)}=3.080 ; p<0.05\right.$, repeated-measures analysis) as well as differences in control versus cyclosporine or nicotine plus cyclosporine-cotreated subjects $(p<0.05$, least significant difference post hoc). C, Total locomotor activity in the initial $15 \mathrm{~min}$ period after a subcutaneous injection of saline or nicotine $(0.35 \mathrm{mg} / \mathrm{kg})$ revealed a significant effect of testing day $\left(F_{(8,480)}=\right.$ $27.064 ; p<0.001)$ and drug treatment $\left(F_{(3,60)}=105.361 ; p<0.001\right)$ with an interaction between test day and drug treatment $\left(F_{(8,480)}=27.064 ; p<0.001\right)$. Coadministration of nicotine and cyclosporine attenuated the locomotor sensitization observed with nicotine administration alone ( $p<0.005$, Tukey's post hoc analysis). $D$, Subjects that received subcutaneous saline injections throughout the $17 \mathrm{~d}$ testing period showed increased locomotor activity in response to an acute nicotine challenge (Nicotine Chall; $0.35 \mathrm{mg} / \mathrm{kg})$ on day $19\left(F_{(3,60)}=\right.$ $36.873 ; p<0.0001)$ with no significant difference between groups that were pretreated with vehicle or cyclosporine $\left(F_{(3,60)}=0.387 ; p=0.536\right)$. Data are presented as the mean \pm SEM. Cyclo, Cyclosporine; Nic, nicotine; Veh, vehicle.

$\mathrm{mg} / \mathrm{kg}$, s.c.) after an $18 \mathrm{~d}$ pretreatment with cyclosporine (15 $\mathrm{mg} / \mathrm{kg}$, i.p.) or vehicle. In this experiment, both groups showed increased locomotor activation in response to the acute nicotine challenge on day $19\left(F_{(3,60)}=36.873 ; p<0.001\right)$, with no significant difference between the two groups $\left(F_{(3,60)}=0.387 ; p=\right.$ 0.536 ) (Fig. 1D). Thus, although calcineurin activity contributes to the locomotor sensitization observed with repeated nicotine exposure, it does not appear to play a role in acute nicotineinduced locomotor activation, consistent with the possibility that calcineurin is important for nicotine-induced locomotor plasticity but not acute signaling.

Although all animals gained weight over the course of the behavioral experiments, repeated-measures analysis revealed an overall effect of treatment $\left(F_{(3,60)}=6.421 ; p<0.005\right.$; data not shown) with decreased weight gain in the cyclosporine group and the nicotine and cyclosporine coadministration group compared with control and nicotine subjects ( $p<0.05$; data not shown). These differences were likely attributable to peripheral immuno- suppressive effects of cyclosporine administration, which were bypassed in subsequent experiments in which cyclosporine was infused directly into the brain. In addition, despite this difference in weight gain with systemic cyclosporine administration, we observed no significant difference in habituation activity between the nicotine group and the nicotine plus cyclosporine coadministration group (Fig. 1B).

\section{Systemic cyclosporine administration alters calcineurin activity in the brain}

To verify that systemic cyclosporine administration inhibited calcineurin activity in the brain, we used Western blot analysis to examine the levels and phosphorylation state of calcineurin target proteins. We hypothesized that cyclosporine administration would decrease calcineurin-mediated dephosphorylation of its target protein, phospho-synapsin I, at calcineurin-sensitive Ser 62/Ser 67 and Ser 549 sites (Jovanovic et al., 2001) and lead to higher levels of this phospho-protein. The results demonstrated that cyclosporine administration $\left(15 \mathrm{mg} \cdot \mathrm{kg}^{-1} \cdot \mathrm{d}^{-1}\right.$, i.p.) increased levels of phospho-synapsin I S62/67 (pSynI S62/67) and S549 (pSynI S549) in the NAc $\left(F_{(3,20)}=54.193 ; p<0.001\right)$ (Fig. $2 B)$, striatum $\left(F_{(3,24)}=16.261 ; p<0.001\right)$ (Fig. $\left.2 B\right)$, and hippocampus $\left(F_{(3,25)}=12.721 ; p<0.005\right)$ (Fig. $\left.2 B\right)$. The cyclosporine-induced increase was also observed when comparing the ratio of pSynI S62/67 to total synapsin I and the ratio of pSynI S549 to total synapsin I (Table 1), with no changes in total synapsin I levels in these regions (Fig. 2D). Furthermore, the effects of calcineurin inhibition on synapsin were specific to calcineurin-mediated dephosphorylation because no significant differences were observed in phosphorylation of synapsin I at Ser 9 (Fig. 2C, Table 1), which is less sensitive to dephosphorylation by calcineurin (Jovanovic et al., 2001). In contrast to subcortical regions, changes in phospho-synapsin I were not observed in the PFC (Fig. 2 B). This likely reflects a lack of bioavailability of systemically administered cyclosporine to cortical regions and suggests that the attenuation of nicotine-mediated behavior resulted from subcortical calcineurin inhibition.

\section{Opposing effects of nicotine and cyclosporine on DARPP32 phosphorylation in the striatum}

Intracellular signaling pathways involving DARPP32 are known to be important for cellular plasticity in response to repeated exposure to drugs of abuse (Greengard et al., 1999). We therefore determined whether DARPP32 levels and phosphorylation state were altered in parallel with the behavioral response to nicotine. DARPP32 is phosphorylated as a result of dopamine receptor activation in the striatum and NAc (Greengard et al., 1999), and this phosphorylation can be modulated by nicotine administration (Hamada et al., 2004; Zhu et al., 2005). In the striatum, we observed an increase in levels of phospho-DARPP32 Thr 34 (pDARPP32 T34) after $40 \mathrm{~d}$ exposure to nicotine $\left(F_{(3,29)}=4.106\right.$; $p=0.05$, ANOVA) (Fig. $3 A$, Table 1). Because phosphorylation at the Thr 34 site is downstream of dopamine receptor activation, this increase in pDARPP32 T34 likely reflects an increase of dopamine availability in the striatum after repeated nicotine exposure. In contrast to nicotine, $40 \mathrm{~d}$ exposure to systemic cyclosporine $(15 \mathrm{mg} / \mathrm{kg})$ led to decreased levels of pDARPP32 T34 in the striatum $\left(F_{(3,29)}=4.113 ; p=0.05\right)$ (Fig. $3 A$, Table 1$)$. Thus, nicotine and cyclosporine administration led to opposing effects on DARPP32 phosphorylation at the Thr 34 site. In addition, subjects that received $40 \mathrm{~d}$ coadministration of nicotine and cyclosporine showed decreased pDARPP32 T34 compared with nicotine-exposed subjects $(p<0.05)$ (Fig. $3 A$, Table 1$)$. Thus, 
cyclosporine administration reversed the nicotine-mediated increase of pDARPP32 T34 in the striatum, suggesting that calcineurin activity normally contributes to this nicotine-mediated increase. The observation that cyclosporine led to increased phosphorylation of the presynaptic calcineurin target pSynI S62/67 and did not increase levels of the postsynaptic calcineurin target pDARPP32 T34 suggests calcineurin inhibition at terminals in the striatum and in cell bodies in subcortical structures such as the VTA contributed to the blockade of the nicotinic effects. In light of these data, we subsequently examined the role of calcineurin activity in the VTA, which sends projection to the striatum and NAc.

\section{Calcineurin inhibition in the VTA attenuates nicotine-mediated locomotor sensitization}

To examine the contribution of calcineurin activity in the VTA to nicotinemediated behavioral changes, we observed locomotor activity in subjects receiving daily administration of nicotine (0.35 $\mathrm{mg} \cdot \mathrm{kg}^{-1} \cdot \mathrm{d}^{-1}$, s.c.) or saline in combination with chronic bilateral VTA infusion of cyclosporine ( $1 \mu \mathrm{g}$ per side per day) or PBS vehicle (Fig. 4A). As in our previous experiments, peak activity was observed in the initial $15 \mathrm{~min}$ after saline or nicotine administration (supplemental Fig. 1B, available at www.jneurosci.org as supplemental material). Analysis of locomotor activity in this initial $15 \mathrm{~min}$ bin across treatment days revealed a significant difference in activity across testing days $\left(F_{(7,273)}=4.955 ; p<0.001\right)$ (Fig. $\left.4 C\right)$ and a significant effect of drug treatment $\left(F_{(3,39)}=74.109 ; p<0.001\right)$ (Fig. $4 C$ ) as well as a significant interaction between day and treatment $\left(F_{(21,273)}=2.228 ; p<\right.$ $0.005)$ with no differences in habituation activity $\left(F_{(3,39)}=1.125 ; p=0.351\right)$ (Fig. $4 B)$. Furthermore, subjects exposed to nicotine showed a sensitized increase in locomotor activity over the $16 \mathrm{~d}$ testing period ( $p<0.001$ vs control) (Fig. $4 C$ ). As with systemic cyclosporine administration, infusion of cyclosporine directly into the VTA did not prevent the development of nicotine-mediated locomotor sensitization ( $p<0.001$ vs control) (Fig. $4 C$ ), but it did attenuate the nicotine-mediated sensitization $(p<0.05)$ (Fig. $4 C)$, demonstrating that calcineurin activity within the VTA is important for a nicotine-mediated change in behavior, although it did not completely prevent the development of nicotine-mediated locomotor sensitization ( $p<0.001$ vs control) (Fig. $4 C)$. After local infusion of cyclosporine in the VTA, we again administered an acute nicotine challenge $(0.35 \mathrm{mg} / \mathrm{kg}$, s.c. $)$ after $16 \mathrm{~d}$ of cyclosporine or vehicle infusion into the VTA. In response to acute nicotine on day 17 , both vehicle- and cyclosporine-exposed animals showed

A) Calcineurin

D) Synapsin I

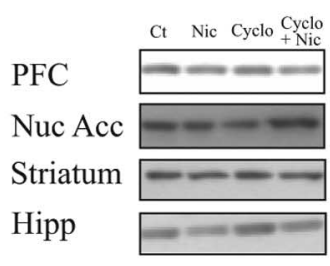

B) pSynapsin I (Ser 62/67)

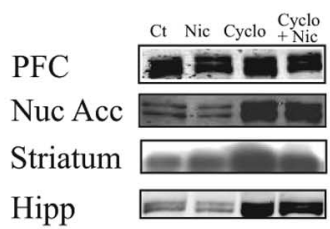

C) pSynapsin I (Ser 9)
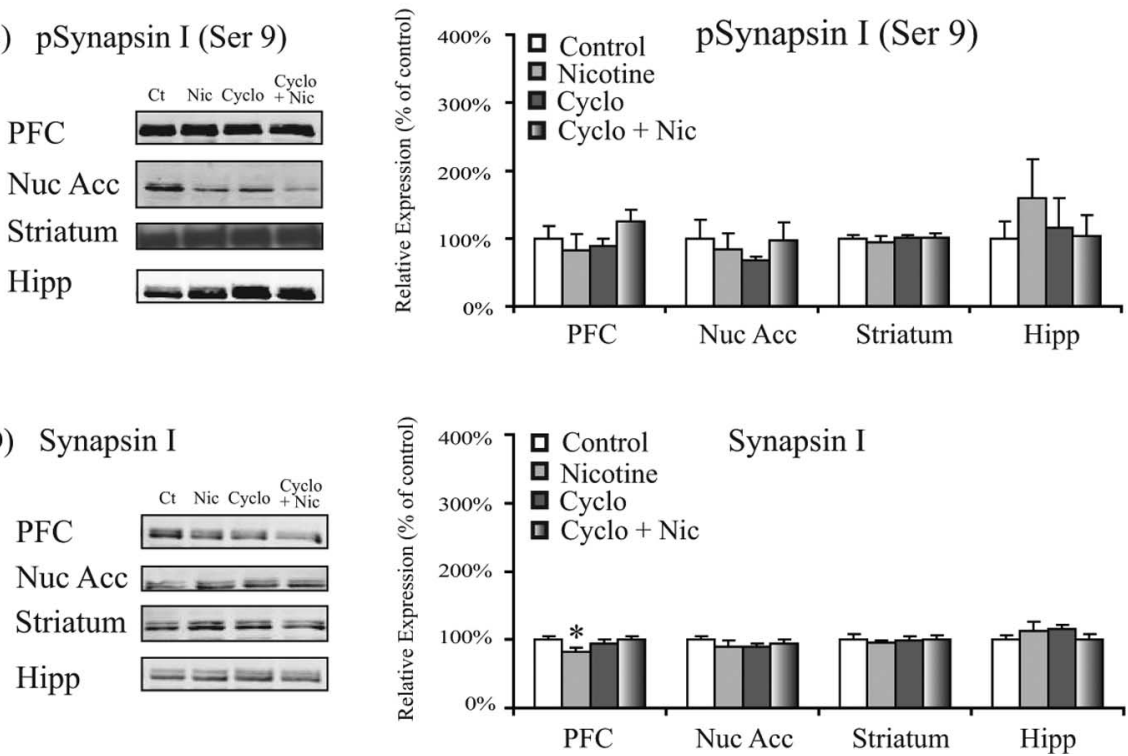

Figure 2. Chronic cyclosporine administration increases the phosphorylation state of calcineurin target proteins in the brain. Levels of calcineurin and the calcineurin target synapsin I after nicotine and cyclosporine administration are shown. $\boldsymbol{A}$, Chronic systemic administration of nicotine $\left(0.35 \mathrm{mg} \cdot \mathrm{kg}^{-1} \cdot \mathrm{d}^{-1}\right.$, s.c.) and cyclosporine $\left(15 \mathrm{mg} \cdot \mathrm{kg}^{-1} \cdot \mathrm{d}^{-1}\right.$, i.p.) did not alter calcineurin levels in the PFC, NAC, striatum, or hippocampus. $B$, Chronic systemic cyclosporine $\left(15 \mathrm{mg} \cdot \mathrm{kg}^{-1} \cdot \mathrm{d}^{-1}\right.$, i.p.) led to increased levels of phospho-Synapsin S62/S67 in the NAc $\left(F_{(3,24)}=54.193 ; p<0.001\right)$, striatum $\left(F_{(3,28)}=16.261 ; p<0.001\right)$, and hippocampus $\left(F_{(3,29)}=12.721 ; p<0.005\right.$, ANOVA). ${ }^{*} p<0.05$. C, Chronic systemic cyclosporine $\left(15 \mathrm{mg} \cdot \mathrm{kg}^{-1} \cdot \mathrm{d}^{-1}\right.$, i.p.) did not alter levels of phospho-Synapsin $S 9$ in any of the regions tested. $D$, Chronic nicotine $\left(0.35 \mathrm{mg} \cdot \mathrm{kg}^{-1} \cdot \mathrm{d}^{-1}\right.$, s.c.) administration led to decreased total synapsin in the $\operatorname{PFC}\left(F_{(1,13)}=0.108 ; p<0.05\right.$, independent-samples $t$ test $)$. Data are presented as the mean $\pm \mathrm{SEM}$. Ct Control; Nic, nicotine; Cyclo, cyclosporine; Nuc Acc, nucleus accumbens; Hipp, hippocampus.

increased locomotor activity $\left(F_{(1,38)}=42.569 ; p<0.001\right.$, ANOVA) (Fig. $4 D$ ) with no significant difference between the two groups $\left(F_{(1,38)}=0.059 ; p=0.810\right.$, ANOVA) (Fig. $\left.4 D\right)$. Thus, calcineurin activity within the VTA contributes to chronic but not acute nicotine locomotor effects.

Cyclosporine treatment did not alter activity in the $30 \mathrm{~min}$ habituation period before saline or nicotine administration when the data were combined; however, the drug could potentially decrease baseline activity in specific time bins, perhaps influencing the subsequent response to nicotine. To address this possibility, we analyzed activity during the habituation period in $5 \mathrm{~min}$ bins across each 30 min session. Peak activity occurred during the 
Table 1. Ratio of phosphorylated-to-total protein for calcineurin target proteins in different brain regions after systemic nicotine (Nic) and cyclosporine (Cyclo) administration

\begin{tabular}{|c|c|c|c|c|c|}
\hline & \multicolumn{3}{|c|}{ pSynapsinl/Synapsinl } & \multicolumn{2}{|l|}{ pDarpp32/ Darpp32 } \\
\hline & Ser 62/67 & Ser 549 & Ser 9 & Thr 34 & Thr 75 \\
\hline \multicolumn{6}{|l|}{ PFC } \\
\hline Control & $100 \pm 16.0$ & $100 \pm 19.8$ & $100 \pm 17.9$ & & \\
\hline $\mathrm{Nic}$ & $121.1 \pm 32.3$ & $120.8 \pm 29.7$ & $99.2 \pm 26.5$ & & \\
\hline Cyclo & $113.2 \pm 10.4$ & $103.5 \pm 18.6$ & $95.1 \pm 13.2$ & & \\
\hline Cyclo + Nic & $77.3 \pm 14.8$ & $129 \pm 25.0$ & $125.6 \pm 17.8$ & & \\
\hline \multicolumn{6}{|l|}{$\mathrm{NAC}$} \\
\hline Control & $100 \pm 6.4$ & $100 \pm 7.5$ & $100 \pm 30.5$ & $100 \pm 8.2$ & $100 \pm 11.1$ \\
\hline $\mathrm{Nic}$ & $97.8 \pm 20.4$ & $94.9 \pm 5.9$ & $93.3 \pm 17.2$ & $109.2 \pm 18.4$ & $93.6 \pm 15.9$ \\
\hline Cyclo & $182.2 \pm 9.9^{* * *}$ & $150.1 \pm 10.1^{* * * *}$ & $78.5 \pm 5.9$ & $69.8 \pm 10.7^{*}$ & $86 \pm 11.1$ \\
\hline Cyclo + Nic & $193.6 \pm 29.7^{* * *}$ & $159.6 \pm 14.4^{* * * *}$ & $105.3 \pm 25.1$ & $79.1 \pm 18.2^{*}$ & $98.8 \pm 34.8$ \\
\hline \multicolumn{6}{|l|}{ Striatum } \\
\hline Control & $100 \pm 17.5$ & $100 \pm 7.8$ & $100 \pm 10.6$ & $100 \pm 14.9$ & $100 \pm 6.8$ \\
\hline $\mathrm{Nic}$ & $117.2 \pm 18.3$ & $114.4 \pm 11.0$ & $93 \pm 7.7$ & $157.7 \pm 24.3^{* * * *}$ & $126.2 \pm 22.6$ \\
\hline Cyclo & $170.7 \pm 15.9^{* *}$ & $123 \pm 11.1$ & $98.3 \pm 7.0$ & $103.7 \pm 12.7$ & $179.7 \pm 17.1^{*}$ \\
\hline Cyclo + Nic & $175.3 \pm 11.8^{* *}$ & $122.2 \pm 8.7$ & $96.4 \pm 5.6$ & $106.6 \pm 8.3$ & $141.9 \pm 23.6^{*}$ \\
\hline \multicolumn{6}{|l|}{ Hipp } \\
\hline Control & $100 \pm 14.2$ & $100 \pm 23.4$ & $100 \pm 24.6$ & & \\
\hline $\mathrm{Nic}$ & $85.3 \pm 15.1$ & $91.4 \pm 21.7$ & $131.7 \pm 41.1$ & & \\
\hline Cyclo & $282.2 \pm 82.0^{* *}$ & $326.5 \pm 75.3^{* * *}$ & $92.4 \pm 31.5$ & & \\
\hline $\mathrm{Cyclo}+\mathrm{Nic}$ & $264 \pm 70.8^{* *}$ & $316.5 \pm 54.5^{* * *}$ & $100.9 \pm 26.4$ & & \\
\hline
\end{tabular}

Shown are protein levels and ratios of phosphorylated-to-total proteins in the PFC, NAC, striatum, and hippocampus (Hipp) of rats after systemic administration of saline vehicle or Nic $\left(0.35 \mathrm{mg} / \mathrm{kg}\right.$, s.c.) in combination with systemic administration of vehicle or Cyclo (15 mg/kg, i.p.) for $40 \mathrm{~d}$. ${ }^{*} p<0.05$ versus non-Cyclo-treated animals (univariate ANOVA); ${ }^{* *} p<0.01$ versus non-Cyclo-treated animals (univariate ANOVA); ${ }^{* * *} p<0.001$ versus non-Cyclo-treated animals (univariate ANOVA); ${ }^{* * *} p<0.08$ versus control ( $t$ test). Data are presented as mean $+\mathrm{SEM}$.

first 5 min of each habituation session and decreased over the subsequent $25 \mathrm{~min}$, with no effect of cyclosporine treatment (supplemental Fig. 2, available at www.jneurosci.org as supplemental material). In addition, cyclosporine infusion had no effect on animal weight throughout the duration of the experiment $\left(F_{(3,39)}=0.623 ; p=0.604\right.$; data not shown $)$, suggesting that the effects of systemic cyclosporine administration were not due to peripheral effects or sickness behavior.

To confirm that the behavioral effects observed with cyclosporine were attributable to calcineurin inhibition, we performed a second experiment using another calcineurin inhibitor, FK506 ( $1 \mu \mathrm{g}$ per side per day). Although cyclosporine and FK506 both inhibit calcineurin, they do so by interacting with distinct molecular targets. Specifically, cyclosporine binds to cyclophilin to form a complex that inhibits calcineurin, whereas FK506 inhibits calcineurin by binding to the FK506-binding protein 12 (FKBP) (Liu et al., 1991). Because cyclosporine-mediated attenuation of nicotine locomotor sensitization was observed during the first $5 \mathrm{~d}$ of testing, locomotor sensitization in the FK506 experiment was examined over a $7 \mathrm{~d}$ period. Peak activity was once again observed in the initial 15 min after nicotine administration, and analysis across testing days revealed a significant effect of treatment $\left(F_{(3,25)}=25.015 ; p<0.001\right)$ (Fig. 5B). Repeated-measures ANOVA showed that nicotine-treated animals demonstrated a significant increase in locomotor activity across testing days $\left(F_{(3,45)}=5.335 ; p<0.005\right)$ (Fig. $\left.5 B\right)$. Consistent with the data in experiments using cyclosporine, FK506 infusion ( $1 \mu \mathrm{g}$ per side per day) into the VTA attenuated this nicotine-mediated locomotor sensitization $\left(F_{(1,15)}=5.555 ; p<0.05\right.$; repeated-measures ANOVA in nicotine-treated animals) (Fig. $5 B$ ). Furthermore, an acute nicotine challenge in vehicle or FK506-pretreated animals led to increased locomotor activity $\left(F_{(3,6)}=6.061 ; p<0.05\right.$; data not shown) with no difference between the two groups, as was previously observed with cyclosporine infusion.

To further confirm that these behavioral effects were specific to calcineurin inhibition, we performed a negative control exper- iment with rapamycin, which binds to FKBP but does not inhibit calcineurin activity (Liu et al., 1991; Yu et al., 2006). Once again, nicotine administration led to locomotor sensitization across testing days $\left(F_{(3,27)}=2.944 ; p=0.05\right)$ (Fig. 5D); however, rapamycin ( $1 \mu \mathrm{g}$ per side per day) infusion into the VTA did not alter this nicotine-mediated locomotor sensitization (Fig. 5D). Consistent with the previous experiment, animals challenged with nicotine $(0.35 \mathrm{mg} / \mathrm{kg})$ on treatment day 8 showed increased locomotor activity $\left(F_{(3,6)}=9.669 ; p<0.05\right.$; data not shown $)$ with no difference between groups pretreated with vehicle or rapamycin. Together, the results with these three compounds suggest that observed attenuation of nicotine-mediated locomotor sensitization is the result of calcineurin inhibition.

\section{Calcineurin inhibition in the NAc does not alter nicotine-mediated locomotor sensitization}

It was not clear from this experiment whether the effects of calcineurin blockade on nicotine-induced locomotor sensitization were specific to the VTA or could be observed in target regions responsive to DA stimulation as well. We therefore measured locomotor activity during daily exposure to nicotine $(0.35$ $\mathrm{mg} / \mathrm{kg}$, s.c.) or saline in combination with chronic bilateral NAc infusion of cyclosporine ( $1 \mu \mathrm{g}$ per side per day) or PBS vehicle. Consistent with experiments infusing cyclosporine into the VTA, we observed a significant difference in locomotor activity across testing day $\left(F_{(7,112)}=2.978 ; p<0.01\right)($ Fig. $5 F)$ and a significant effect of drug treatment $\left(F_{(3,16)}=68.533 ; p<0.001\right)$ (Fig. $5 F$ ) along with a significant interaction between day and treatment $\left(F_{(21,112)}=2.417 ; p<0.005\right)$ (Fig. $\left.5 F\right)$; however, nicotine exposure led to a sensitized increase in locomotor activity $(p<0.005$ vs control) (Fig. $5 F$ ) that was not altered by cyclosporine infusion into the NAc. Thus, calcineurin activity in the NAc does not appear to play a critical role in nicotine-induced sensitization. Furthermore, subjects that were exposed to cyclosporine or vehicle for $16 \mathrm{~d}$ both showed increased locomotor activity in response to an acute nicotine challenge on day $17\left(F_{(1,14)}=31.925 ; p<\right.$ 0.001; data not shown) with no difference between the two groups $\left(F_{(1,14)}=0.750 ; p=0.401\right.$; data not shown). Together, these results suggest that the effects of calcineurin inhibition on locomotor sensitization are specific to the VTA.

\section{Systemic nicotine and VTA cyclosporine effects on levels of calcineurin target proteins}

We used Western blot analysis to examine levels of the calcineurin target protein pSynI S62/67 to determine whether cyclosporine altered calcineurin activity in the VTA and in target regions of dopamine projections, potentially through action of cyclosporine on proteins in dopaminergic terminals. Cyclosporine administration into the VTA did not alter pSynI S62/67 (Table 2); however, tissue was examined after cannulation and chronic drug infusion. Thus, the effect of minimal tissue damage could not be negated. Nonetheless, a significant decrease in pSynI S62/67 was observed in rats treated with nicotine compared with subjects receiving nicotine in combination with cyclosporine in- 
fusion into the VTA $(p<0.05)$ (Table 1$)$. Thus, calcineurin inhibition in the VTA appears to block a nicotine-mediated decrease in pSynI S62/67. The decrease in levels of presynaptic synapsin I, which is known to modulate neurotransmitter release and endocytosis (Cousin and Robinson, 2001; Hilfiker et al., 2005) could impact release of neurotransmitters in the VTA, suggesting a potential mechanism through which calcineurin activity in the VTA might contribute to nicotinemediated plasticity.

There was a trend toward an increase in calcineurin levels in the VTA after chronic cyclosporine exposure $\left(F_{(3,33)}=3.301\right.$; $p<0.08$, ANOVA) (Table 2); however, it is unlikely that this led to an increase in VTA calcineurin activity, because cyclosporine was continuously infused into this region. In addition, intra-VTA cyclosporine administration did not alter synapsin I phosphorylation in the NAc, providing further evidence that the behavioral effects of cyclosporine administration are specific to the VTA. Although these data do not rule out the possibility that infused cyclosporine may have diffused outside of the VTA to some extent, they suggest that cyclosporine infusions did, in fact, penetrate into the VTA and was not acting in the NAc.

\section{Discussion}

Our findings provide the first demonstration that calcineurin activity contributes to behavioral changes after repeated nicotine administration. The fact that calcineurin inhibitors attenuate nicotineinduced behavioral sensitization, but not acute nicotine locomotor activation, suggests that calcineurin plays a role in the long-term changes associated with repeated nicotine exposure. In addition, the opposing effects of nicotine and cyclosporine on pDARPP32 T34 in the striatum reveals a potential mechanism by which calcineurin could promote nicotinemediated locomotor sensitization. The ability of calcineurin inhibitors in the VTA to attenuate nicotine-mediated behavior provides additional evidence for the role of calcineurin as a modulator of nicotinemediated plasticity within the VTA. Together, the findings demonstrate a novel role for VTA calcineurin activity in the plastic and behavioral changes associated with repeated nicotine exposure.

Although the critical role of the mesolimbic dopamine system in nicotine-mediated behavior has been highlighted in several studies (Corrigall et al., 1994; Fu et al., 2000; Ferrari et al., 2002), the intracellular signaling pathways, such as those involving calcineurin, important for these behavioral effects have not been

B) Darpp 32

D) Darpp 32

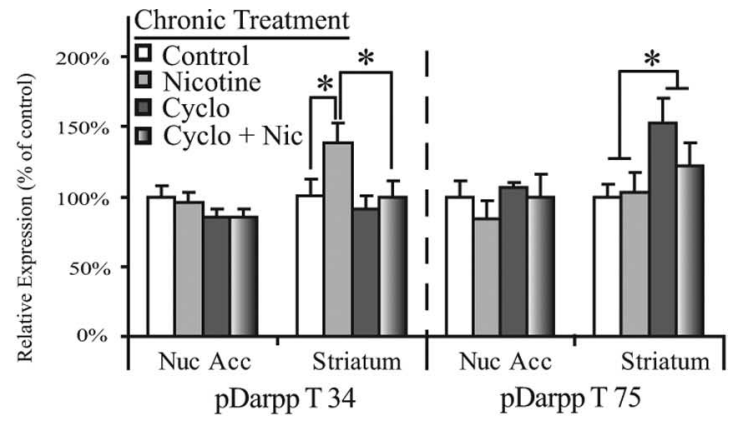

(after chronic administration)
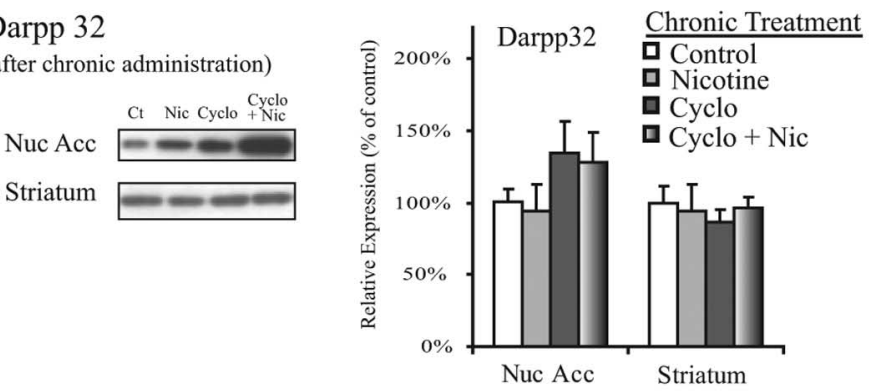

C) pDarpp32 (Thr 34 and 75) (after acute administration)
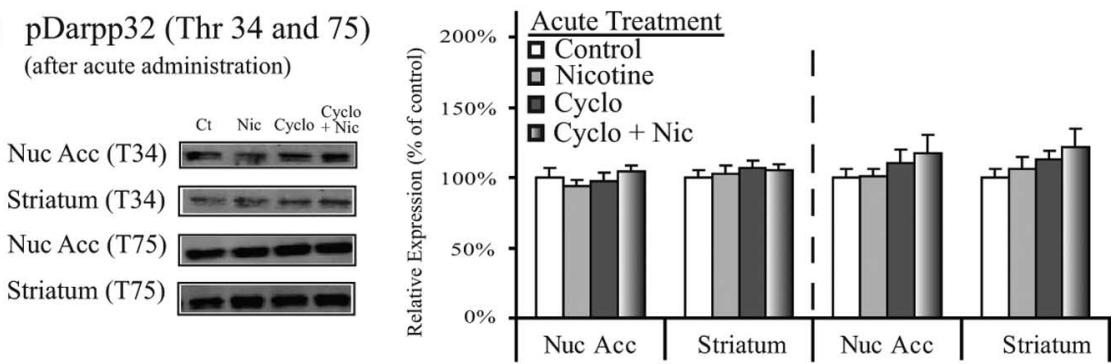

pDarpp T 34

pDarpp T 75

(after acute administration)

$\mathrm{Ct} \quad \mathrm{Nic}$ Cyclo + Cyclo $+\mathrm{Nic}$

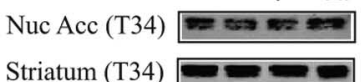

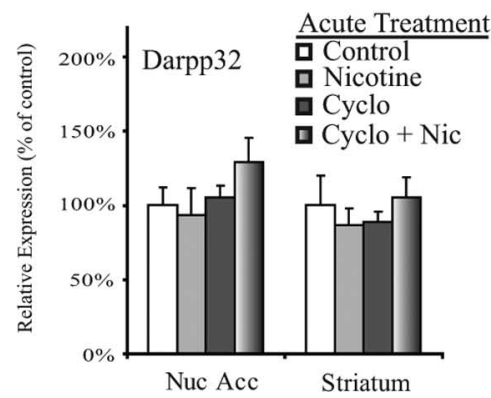

Figure 3. Chronic cyclosporine administration blocks the ability of chronic nicotine to activate DARPP32. DARPP32 levels after chronic or acute nicotine and cyclosporine administration are shown. $A$, Chronic nicotine $\left(0.35 \mathrm{mg} \cdot \mathrm{kg}^{-1} \cdot \mathrm{d}^{-1}\right.$, s.c.) leads to increased pDARPP32 T34 in the striatum $\left(F_{(3,30)}=4.106 ; p=0.05\right.$, ANOVA), whereas cyclosporine $\left(15 \mathrm{mg}^{\circ} \mathrm{kg}^{-1} \cdot \mathrm{d}^{-1}\right.$, i.p. $)$ leads to decreased pDARPP32 T34 in the striatum $\left(F_{(3,30)}=4.113 ; p=0.05\right.$, ANOVA). Coadministration of nicotine $(0.35$ $\left.\mathrm{mg} \cdot \mathrm{kg}^{-1} \cdot \mathrm{d}^{-1}, \mathrm{s.c}\right)$ and cyclosporine $\left(15 \mathrm{mg} \cdot \mathrm{kg}^{-1} \cdot \mathrm{d}^{-1}\right.$, i.p.) decreases pDARPP32 T34 levels in the striatum compared with nicotine $\left(0.35 \mathrm{mg} \cdot \mathrm{kg}^{-1} \cdot \mathrm{d}^{-1}\right.$, s.c.)-treated subjects ( $p<0.05$, independent-samples $t$ test). Cyclosporine administration (15 $\mathrm{mg} \cdot \mathrm{kg}^{-1} \cdot \mathrm{d}^{-1}$, i.p.) also increased levels of pDARPP32 T75 in the NAc $\left(F_{(3,30)}=5.134 ; p<0.05\right.$, ANOVA). ${ }^{*} p<0.05$. B, Chronic drug treatment did not alter DARPP32 levels in the NAc or striatum. $C, D$, Acute administration of nicotine $(0.35 \mathrm{mg} / \mathrm{kg}$, s.c.) and cyclosporine ( $15 \mathrm{mg} / \mathrm{kg}$, i.p.) did not alter levels of pDARPP32 T34, pDARPP32 T75, or total DARPP32 in the NAc or striatum. Data are presented as the mean \pm SEM. Ct, Control; Nic, nicotine; Cyclo, cyclosporine; Nuc Acc, nucleus accumbens.

identified. Nicotine could potentially lead to changes in synaptic strength through modulation of glutamate and dopamine release (Imperato et al., 1986; Toth et al., 1992; Fu et al., 2000) and through actions at a number of identified intracellular signaling molecules such as protein kinase A (PKA) and its downstream targets including DARPP32, ERK (extracellular signal-regulated protein kinase), and CREB (Nakayama et al., 2001; Brunzell et al., 


\section{Cyclosporine infusion into VTA}

A) Locomotor Paradigm

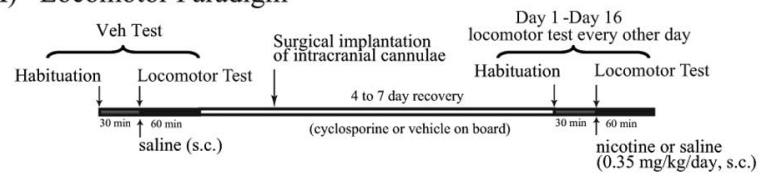

B) Total Habituation Activity

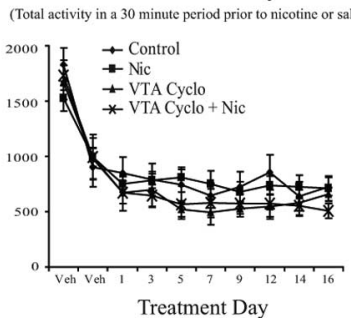

C) Post-Injection Locomotor Activity (Total activity in a 15 minute period following nicotine or saline)

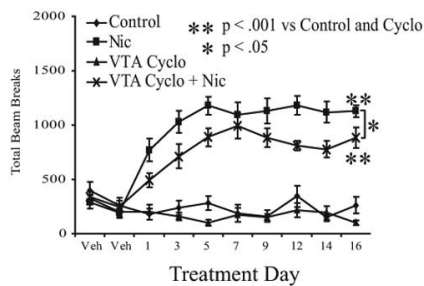

D) Acute Nicotine Challenge

(Total activity in a 15 minute period following nicotine or saline)

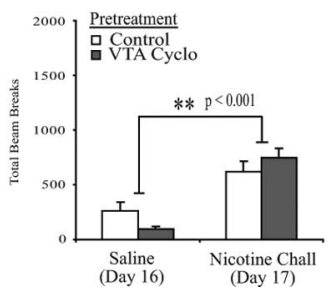

Figure 4. Intra-VTA cyclosporine administration decreases nicotine-induced locomotor sensitization. Repeated systemic nicotine administration leads to locomotor sensitization in Sprague Dawley rats that is attenuated by chronic cyclosporine infusion into the VTA $(n=9-12$ per group). $\boldsymbol{A}$, Locomotor testing paradigm and timeline. $\boldsymbol{B}$, Total activity during the $30 \mathrm{~min}$ habituation period before saline or nicotine $(0.35 \mathrm{mg} / \mathrm{kg}$, s.c.) administration during testing days 1-16 revealed no effect of treatment on prechallenge lomocotor activity. C, Total locomotor activity during a $15 \mathrm{~min}$ period after a subcutaneous injection of saline vehicle or nicotine $(0.35 \mathrm{mg} / \mathrm{kg})$ revealed a significant effect of testing day $\left(F_{(7,273)}=4.955 ; p<0.001\right)$ and drug treatment $\left(F_{(3.39)}=74.109 ; p<0.001\right)$ as well as a significant interaction between day and treatment $\left(F_{(21,273)}=2.228 ; p<0.005\right)$. Coadministration of systemic nicotine $(0.35$ $\mathrm{mg} \cdot \mathrm{kg}^{-1} \cdot \mathrm{d}^{-1}$ ) with cyclosporine infusion into the VTA (1 $\mu \mathrm{g}$ per side per day) attenuated the locomotor sensitization observed with nicotine administration alone $(p<0.05$, Tukey's post hoc analysis). D, Subjects that received daily saline administration for $16 \mathrm{~d}$ showed increased locomotor activity in response to an acute nicotine challenge (Nicotine Chall) on day $17\left(F_{(1,38)}\right.$ $=42.569 ; p<0.001$, ANOVA) with no significant difference between those that had had received chronic cyclosporine ( $1 \mu \mathrm{g}$ per side per day) or vehicle infusions into the VTA. Data are presented as the mean \pm SEM. Veh, Vehicle; Nic, nicotine; Cyclo, cyclosporine.

2003; Hamada et al., 2004; Valjent et al., 2005). Interestingly, calcineurin can alter the activity of a majority of these proteins. Calcineurin downregulates several PKA targets including DARPP32 and CREB, as well as AMPA and NMDA receptors and sodium and calcium channels (Greengard et al., 1999; Winder and Sweatt, 2001; Day et al., 2002; Hu et al., 2005). This regulation can occur through direct calcineurin-mediated dephosphorylation of these proteins (King et al., 1984; Chen et al., 1995; Day et al., 2002) and through calcineurin-mediated disinhibition of protein phosphatase 1 (Greengard et al., 1999).

The majority of the research addressing the contribution of calcineurin to the mechanisms underlying drug abuse has focused on the effects of the calcineurin target, DARPP32, in the striatum and NAc (Greengard et al., 1999; Hamada et al., 2004). Several drugs of abuse, including cocaine and nicotine, can increase phosphorylation of DARPP32 at the T34 site (Zhu et al., 2005; Lynch et al., 2006), and this phosphorylation appears to be critical for behavioral responses to cocaine (Zachariou et al., 2006). Although nicotine-mediated DARPP32 activation was not
A) Pre-Injection Habituation Acitivity

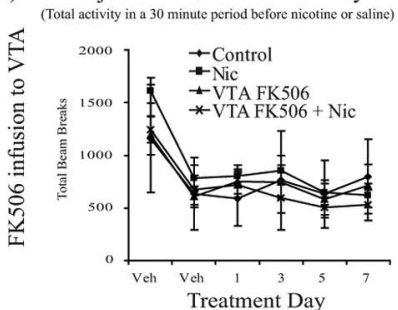

C) Pre-Injection Habituation Acitivity (Total activity in a 30 minute period before nicotine or saline)

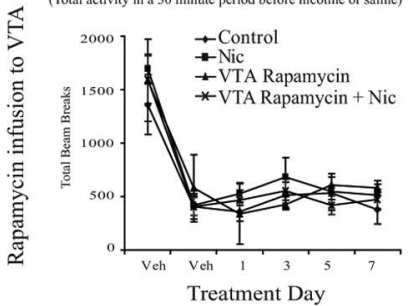

E) Pre-Injection Habituation Acitivity (Total activity in a 30 minute period before nicotine or saline)

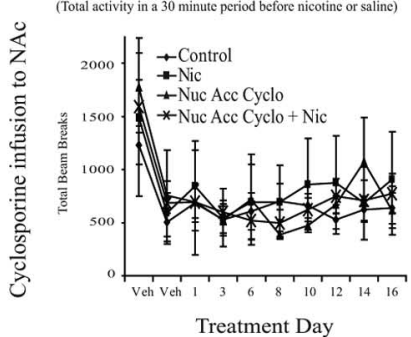

B) Post-Injection Locomotor Activity (Total activity in a 15 minute period following nicotine or saline)

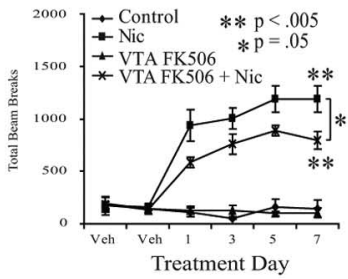

D) Post-Injection Locomotor Activity

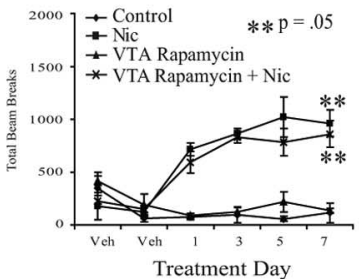

F) Post-Injection Locomotor Activity

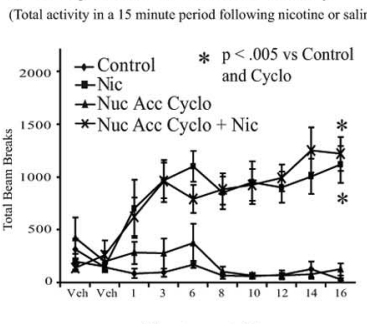

Treatment Day (Total activity in a 15 minute period following nicotinc or saline

Figure 5. VTA FK506 decreases, whereas VTA rapamycin and NAc cyclosporine do not alter, nicotine-induced locomotor sensitization. Repeated, systemic nicotine administration leads to locomotor sensitization in Sprague Dawley rats that is attenuated by chronic FK506, but not rapamycin, infusion into the VTA ( $n=4-8$ per group) and is not altered by chronic cyclosporine infusion into the NAC ( $n=4-8$ per group. $\boldsymbol{A}$, FK506 into VTA. Total activity during the 30 min habituation period before saline or nicotine $(0.35 \mathrm{mg} / \mathrm{kg}$, s.c.) administration on each day of testing demonstrated no effect of treatment. $\boldsymbol{B}$, FK506 into VTA. Total locomotor activity during the initial $15 \mathrm{~min}$ period after saline vehicle or nicotine $(0.35 \mathrm{mg} / \mathrm{kg})$ administration revealed locomotor sensitization in nicotine-treated animals $\left(F_{(3,45)}=5.335 ; p<0.005\right)$. FK506 ( $1 \mu \mathrm{g}$ per side per day) infusion into the VTA significantly attenuated this locomotor sensitization $\left(F_{(1,15)}=5.555 ; p<0.05\right)$. C, Rapamycin into VTA. Total activity during the habituation period before nicotine or saline administration on each day of testing revealed no effect of treatment. $\boldsymbol{D}$, Rapamycin into VTA. Total locomotor activity in the 15 min after saline or nicotine $(0.35 \mathrm{mg} / \mathrm{kg})$ revealed locomotor sensitization in nicotine-treated animals $\left(F_{(3,27)}=\right.$ $2.944 ; p=0.05$ ) with no effect of rapamycin coadministration. $\boldsymbol{E}$, Cyclosporine into NAc. Total activity during the $30 \mathrm{~min}$ habituation period before saline or nicotine $(0.35 \mathrm{mg} / \mathrm{kg}$, s.c.) administration on each day of testing demonstrated no effect of treatment. $\boldsymbol{F}$, Cyclosporine into NAC. Total locomotor activity in the 15 min period after subcutaneous injection of saline vehicle or nicotine revealed a significant effect of testing day $\left(F_{(7,112)}=2.978 ; p<0.01\right)$ and drug treatment $\left(F_{(3,16)}=68.533 ; p<0.001\right)$ along with a significant interaction between day and treatment $\left(F_{(21,112)}=2.417 ; p<0.005\right)$. In addition, nicotine administration led to locomotor sensitization ( $p<0.005$ vs control) that was not altered by intra-NAc infusion of cyclosporine (1 $\mu$ g per side per day). Nic, nicotine; Cyclo, cyclosporine; Nuc Acc, nucleus accumbens; Veh, vehicle.

observed in the NAc in the current work, this may have resulted from tissue sampling that did not distinguish between core and shell subregions. Because DARPP32 T34 phosphorylation occurs downstream of dopamine $\mathrm{D}_{1}$ receptor activation (Greengard et al., 1999), and nicotine leads to sensitization of dopamine release in the core and not the shell (Iyaniwura et al., 2001), nicotinemediated DARPP32 activation would be more likely to occur in the NAc core. Thus, samples containing both NAc core and shell tissue may have diluted the effect of a core-specific increase in phosphorylated DARPP32. Nevertheless, the observed blockade 
of nicotine-mediated DARPP32 in the striatum after calcineurin inhibition demonstrates a role for calcineurin in nicotinemediated intracellular signaling in dopaminergic target regions and provides one potential mechanism for the complex contributions of calcineurin to nicotinemediated behavior.

Because calcineurin can dephosphorylate DARPP32, one would predict that calcineurin inhibition would increase DARPP32 phosphorylation. Instead, we saw that nicotine increased DARPP32 phosphorylation, and this was reversed by inhibiting calcineurin. These results suggest that calcineurin is not activated in the striatum after nicotine administration but, rather, that calcineurin activity in other regions of the mesolimbic circuit is involved in nicotine-mediated locomotor sensitization. For example, systemic cyclosporine administration inhibited calcineurin activity in presynaptic terminals because phosphorylation of the synaptic calcineurin target protein synapsin I was increased at the S62/67 and S549 sites after calcineurin blockade. An increase in synapsin I phosphorylation has been shown to increase both the number of vesicles in the readily releasable pool and the likelihood of neurotransmitter release during stimulation (Huttner et al., 1983; Bahler and Greengard, 1987; Greengard et al., 1993; Jovanovic et al., 2000). Thus, calcineurin inhibition could potentially increase the release of neurotransmitters such as glutamate, dopamine, and GABA in multiple brain regions. Our data, in particular, suggest that calcineurin inhibition at different sites within the mesolimbic circuit attenuated nicotinemediated dopaminergic responses, thus reversing nicotinemediated DARPP32 activation. One potential mechanism by which this could occur is through increased GABA release in regions that project to the dorsal and ventral striatum to limit DARPP32 activation. Specifically, we demonstrate an important role for calcineurin activity in the VTA, where such activity can contribute to the plasticity associated with nicotine administration.

Nicotine is thought to induce synaptic plasticity in the VTA through modulation of glutamatergic activity. Nicotine administration in vivo leads to increased glutamate release in the VTA (Fu et al., 2000; Ferrari et al., 2002), whereas nicotine application to VTA slices leads to increased glutamatergic transmission (Mansvelder et al., 2002). In addition, nAChRs on glutamatergic terminals desensitize more slowly than those on GABAergic terminals, leading to a shift toward glutamatergic drive in the VTA after repeated nicotine exposure (Mansvelder et al., 2002). The ability of nicotine to regulate glutamatergic tone is likely to have behavioral consequences, because nicotine administration into the VTA leads to increased locomotor activity (Ferrari et al., 2002), and nicotine self-administration increases GluR2 and GluR3 glutamate receptor subunit levels in the VTA (Wang et al., 2007). Systemic administration of NMDA antagonists, in contrast, attenuates nicotine-mediated locomotor sensitization (Shoaib et al., 1994), whereas NMDA receptor antagonist administration into the VTA attenuates nicotine-mediated dopamine release in the accumbens (Svensson et al., 1998) and attenuates the excita- tory effects of nicotine in midbrain slices (Grillner and Svensson, 2000). Together, these data demonstrate an important role for glutamatergic and excitatory tone in the VTA in response to nicotine administration and suggest that these effects play an important role in nicotine-mediated behavior.

Calcineurin could be involved in modulating nicotineinduced glutamatergic effects in the VTA through several different mechanisms. For instance, calcineurin inhibition by cyclosporine in cultured cortical neurons increases the rate of recovery from desensitization of $\alpha_{4} \beta_{2}$ nAChRs (Marszalec et al., 2005). This nAChR subtype is thought to be located on GABAergic terminals (Mansvelder et al., 2002) and cell bodies (Klink et al., 2001) in the VTA. Together, these data suggest that calcineurin could contribute to the profound desensitization of $\alpha_{4} \beta_{2}$ nAChRs at GABAergic terminals after nicotine exposure, thus promoting the shift from mixed glutamatergic/GABAergic responses to acute nicotine in the VTA to decreased GABAergic response to chronic nicotine. In addition, calcineurin can also inhibit GABAergic transmission through direct actions at $\mathrm{GABA}_{\mathrm{A}}$ receptors. In fact, calcineurin-mediated dephosphorylation of $\mathrm{GABA}_{\mathrm{A}}$ channels leads to decreased $\mathrm{GABA}_{\mathrm{A}}$ receptor activity, increased $\mathrm{GABA}_{\mathrm{A}}$ receptor desensitization rates, and LTD of inhibitory transmission (Yakel, 1997; Groth et al., 2003; Wang et al., 2003). This calcineurin-mediated dephosphorylation of $\mathrm{GABA}_{\mathrm{A}}$ receptors is also necessary for EPSP-spike coupling, whereby an EPSP is more likely to elicit an action potential (Lu et al., 2000). Through these potential mechanisms, calcineurin activity may be able to support increased excitatory tone in the VTA that could then promote a nicotine-mediated increase in dopamine release and locomotor sensitization.

The ability of nicotine to activate calcineurin activity in the VTA could be attributable to many nicotine-mediated signaling pathways. Whereas nicotine-induced calcium influx through nAChRs and L-type calcium channels (LTCCs) results in calcineurin activation in cultured cortical neurons (Stevens et al., 
2003), these mechanisms have not been examined in the VTA. Calcium influx through LTCCs is an attractive mechanism for nicotine-dependent calcineurin activation because these calcium channels are critical for several nicotine-mediated behaviors. LTCC antagonists block acute nicotine-dependent locomotor activation and attenuate chronic nicotine-mediated locomotor sensitization (Hart et al., 1996; Biala, 2003). In addition, chronic nicotine administration increases the expression of various LTCC subunits in the cortex (Hayashida et al., 2005). Thus, calcineurin may serve as one of the critical effector proteins downstream of chronic nicotine-mediated LTCC activation to support nicotine-mediated behavior.

This study provides the first evidence that VTA calcineurin activity contributes to nicotine-mediated behavior and highlights the need for additional research to further examine the mechanism of action of calcineurin in this region. Although calcineurin could promote excitation in the VTA through several different mechanisms, additional experimentation is necessary to determine which of these mechanisms are crucial for nicotinemediated plasticity within this region. Although our examination focused on nicotine-mediated locomotor sensitization, we suggest that calcineurin within the VTA could also contribute to other nicotine-mediated behaviors. Given that plasticity within the VTA modulates nicotine conditioned place preference (Laviolette and Van der Kooy, 2003) and self-administration (Corrigall et al., 1994), calcineurin-mediated plasticity could contribute to these behaviors as well. Together, such research will provide new insights into the underlying mechanisms of nicotine signaling contributing to reward and reinforcement.

\section{References}

Bahler M, Greengard P (1987) Synapsin I bundles F-actin in a phosphorylation-dependent manner. Nature 326:704-707.

Biala G (2003) Calcium channel antagonists suppress nicotine-induced place preference and locomotor sensitization in rodents. Pol J Pharmacol 55:327-335.

Brunzell D, Russell D, Picciotto M (2003) In vivo nicotine treatment regulates mesocorticolimbic CREB and ERK signaling in C57Bl/6 J mice. J Neurochem 84:1431-1441.

Centers for Disease Control and Prevention (2006) Tobacco use among adults-United States, 2005. MMWR Morb Mortal Wkly Rep 55:11451148.

Chen TC, Law B, Kondratyuk T, Rossie S (1995) Identification of soluble protein phosphatases that dephosphorylate voltage-sensitive sodium channels in rat brain. J Biol Chem 270:7750-7756.

Corrigall W, Coen K, Adamson K (1994) Self-administered nicotine activates the mesolimbic dopamine system through the ventral tegmental area. Brain Res 653:278-284.

Cousin M, Robinson P (2001) The dephosphins: dephosphorylation by calcineurin triggers synaptic vessible endocytosis. Trends Neurosci 24:659-665.

Day M, Olson P, Platzer J, Striessnig J, Surmeier D (2002) Stimulation of $5-\mathrm{HT}(2)$ receptors in prefrontal pyramidal neurons inhibits Ca.(v)1.2 L type $\mathrm{Ca}(2+)$ currents via a PLCbeta/IP3/calcineurin signaling cascade. J Neurophysiol 87:2490-2504.

Donatsch P, Ryffel B (1986) Pharmacokinetics of cyclosporine in toxicological studies. Transplant Proc 28:71-76.

Ferrari R, Le Novere N, Picciotto M, Changeux J, Zoli M (2002) Acute and long-term changes in the mesolimbic dopamine pathway after systemic or local single nicotine injections. Eur J Neurosci 15:1810-1818.

Fu Y, Matta S, Gao W, Brower V, Sharp B (2000) Systemic nicotine stimulates dopamine release in nucleus accumbens: re-evaluation of the role of $\mathrm{N}$-methyl-D-aspartate receptors in the ventral tegmental area. J Pharamcol Exp Ther 294:458-465.

Greengard P, Valtorta F, Czernik AJ, Benfenati F (1993) Synaptic vesicle phosphoproteins and regulation of synaptic function. Science 259:780-785.
Greengard P, Allen PB, Nairn AC (1999) Beyond the dopamine receptor: the DARPP-32/protein phosphatase-1 cascade. Neuron 23:435-447.

Grillner P, Svensson TH (2000) Nicotine-induced excitation of midbrain dopamine neurons in vitro involves ionotropic glutamate receptor activation. Synapse 38:1-9.

Groth RD, Dunbar RL, Mermelstein PG (2003) Calcineurin regulation of neuronal plasticity. Biochem Biophys Res Commun 311:1159-1171.

Hamada M, Higashi H, Nairn A, Greengard P, Nishi A (2004) Differential regulation of dopamine D1 and D2 signaling by nicotine in neostriatal neurons. J Neurochem 90:1094-1103.

Hart C, Kisro NA, Robinson SL, Ksir C (1996) Effects of the calcium channel blocker nimodipine on nicotine-induced locomotion in rats. Psychopharmacology (Berl) 128:359-361.

Hayashida S, Katsura M, Torigoe F, Tsujimura A, Ohkuma S (2005) Increased expression of L-type high voltage-gated calcium channel alpha1 and alpha2/delta subunits in mouse brain after chronic nicotine administration. Brain Res Mol Brain Res 135:280-284.

Hilfiker S, Benfenati F, Doussau F, Nairn A, Czernik A, Augustine G, Greengard P (2005) Structural domains involved in the regulation of transmitter release by synapsins. J Neurosci 25:2658-2669.

Hu XT, Ford K, White FJ (2005) Repeated cocaine administration decreases calcineurin (PP2B) but enhances DARPP-32 modulation of sodium currents in rat nucleus accumbens neurons. Neuropsychopharmacology 30 : 916-926.

Huttner WB, Schiebler W, Greengard P, De Camilli P (1983) Synapsin I (protein I), a nerve terminal-specific phosphoprotein. III. Its association with synaptic vesicles studied in a highly purified synaptic vesicle preparation. J Cell Biol 96:1374-1388.

Imperato A, Mulas A, Di Chiara G (1986) Nicotine preferentially stimulates dopamine release in the limbic system of freely moving rats. Eur J Pharmacol 132:337-338.

Iyaniwura T, Wright A, Balfour D (2001) Evidence that mesoaccumbens dopamine and locomotor responses to nicotine in the rat are influenced by pretreatment dose and strain. Psychopharmacology 158:73-79.

Jovanovic J, Sihra T, Nairn A, Hemmings HJ, Greengard P, Czernik A (2001) Opposing changes in phosphorylation of specific sites in synapsin I during $\mathrm{Ca}^{2+}$-dependent glutamate release in isolated nerve terminals. J Neurosci 21:7944-7953.

Jovanovic JN, Czernik AJ, Fienberg AA, Greengard P, Sihra TS (2000) Synapsins as mediators of BDNF-enhanced neurotransmitter release. Nat Neurosci 3:323-329.

King MM, Huang CY, Chock PB, Nairn AC, Hemmings Jr HC, Chan KF, Greengard P (1984) Mammalian brain phosphoproteins as substrates for calcineurin. J Biol Chem 259:8080-8083.

Kita T, Okamoto M, Nakashima T (1992) Nicotine-induced sensitization to ambulatory stimulant effect produced by daily administration into the ventral tegmental area and the nucleus accumbens in rats. Life Sci 50:583-590.

Klink R, de Kerchove d'Exaerde A, Zoli M, Changeux JP (2001) Molecular and physiological diversity of nicotinic acetylcholine receptors in the midbrain dopaminergic nuclei. J Neurosci 21:1452-1463.

Laviolette S, Van der Kooy D (2003) Blockade of mesolimbic dopamine transmission dramatically increases sensitivity to the rewarding effects of nicotine in the ventral tegmental area. Mol Psychiatry 8:50-59.

Laviolette S, Van der Kooy D (2004) The neurobiology of nicotine addiction: bridging the gap from the molecules to behavior. Nat Rev Neurosci 5:55-65.

Lee JI, Ahnn J (2004) Calcineurin in animal behavior. Mol Cells 17:390-396.

Lisman J (1989) A mechanism for the Hebb and the anti-Hebb processes underlying learning and memory. Proc Natl Acad Sci USA 86:9574-9578.

Liu J, Farmer Jr JD, Lane WS, Friedman J, Weissman I, Schreiber SL (1991) Calcineurin is a common target of cyclophilin-cyclosporin A and FKBPFK506 complexes. Cell 66:807-815.

Lu YM, Mansuy IM, Kandel ER, Roder J (2000) Calcineurin-mediated LTD of GABAergic inhibition underlies the increased excitability of CA1 neurons associated with LTP. Neuron 26:197-205.

Lynch WJ, Kiraly DD, Caldarone BJ, Picciotto MR, Taylor JR (2006) Effect of cocaine self-administration on striatal PKA-regulated signaling in male and female rats. Psychopharmacology (Berl) 191:263-271.

Mansvelder H, Keath J, McGehee D (2002) Synaptic mechanisms underlie nicotine-induced excitability of brain reward areas. Neuron 33:905-919. 
Marszalec W, Yeh JZ, Narahashi T (2005) Desensitization of nicotine acetylcholine receptors: modulation by kinase activation and phosphatase inhibition. Eur J Pharmacol 514:83-90.

McGehee DS, Role LW (1995) Physiological diversity of nicotinic acetylcholine receptors expressed by vertebrate neurons. Annu Rev Physiol 57:521-546.

Nakayama H, Numakawa T, Ikeuchi T, Hatanaka H (2001) Nicotineinduced phosphorylation of extracellular signal-regulated protein kinase and CREB in PC12h cells. J Neurochem 79:489-498.

Panagis G, Nisell M, Nomikos GG, Chergui K, Svensson TH (1996) Nicotine injections into the ventral tegmental area increase locomotion and Fos-like immunoreactivity in the nucleus accumbens of the rat. Brain Res 730:133-142.

Picciotto M (1998) Common aspects of the action of nicotine and other drugs of abuse. Drug Alcohol Depend 51:165-172.

Saal D, Dong Y, Bonci A, Malenka R (2003) Drugs of abuse and stress trigger a common synaptic adaptation in dopamine neurons. Neuron 37:577-582.

Stevens T, Krueger S, Fitzsimonds R, Picciotto M (2003) Neuroprotection by nicotine in mouse primary cortical cultures involves activation of calcineurin and L-type calcium channel inactivation. J Neurosci 23:10093-10099.

Svensson TH, Mathe JM, Nomikos GG, Schilstrom B (1998) Role of excitatory amino acids in the ventral tegmental area for central actions of non-competitive NMDA-receptor antagonists and nicotine. Amino Acids 14:51-56.

Toth E, Sershen H, Hashim A, Vizi ES, Lajtha A (1992) Effect of nicotine on extracellular levels of neurotransmitters assessed by microdialysis in various brain regions: role of glutamic acid. Neurochem Res 17:265-271.

Valjent E, Pascoli V, Svenningsson P, Paul S, Enslen H, Corvol J, Stipanovich
A, Caboche J, Lombroso P, Nairn A, Greengard P, Herve D, Girault J (2005) Regulation of a protein phosphatase cascade allows convergent dopamine and glutamate signals to activate ERK in the striatum. Proc Natl Acad Sci USA 102:491-496.

Wang F, Chen H, Steketee JD, Sharp BM (2007) Upregulation of ionotropic glutamate receptor subunits within specific mesocorticolimbic regions during chronic nicotine self-administration. Neuropsychopharmacology 32:103-109.

Wang J, Liu S, Haditsch U, Tu W, Cochrane K, Ahmadian G, Tran L, Paw J, Wang Y, Mansuy I, Salter MM, Lu YM (2003) Interaction of calcineurin and type-A GABA receptor $\gamma 2$ subunits produces long-term depression at CA1 inhibitory synapses. J Neurosci 23:826-836.

Winder DG, Sweatt JD (2001) Phosphatases in hippocampal synaptic plasticity. Nat Rev Neurosci 2:461-474.

Yakel JL (1997) Calcineurin regulation of synaptic function: from ion channels to transmitter release and gene transcription. Trends Pharmacol Sci 18:124-134.

Yu DY, Luo J, Bu F, Zhang W, Wei Q (2006) Effects of cyclosporin A, FK506 and rapamycin on calcineurin phosphatase activity in mouse brain. IUBMB Life 58:429-433.

Zachariou V, Sgambato-Faure V, Sasaki T, Svenningsson P, Berton O, Fienberg AA, Nairn AC, Greengard P, Nestler EJ (2006) Phosphorylation of DARPP-32 at threonine-34 is required for cocaine action. Neuropsychopharmacology 31:555-562.

Zhu H, Lee M, Guan F, Agatsuma S, Scott D, Fabrizio K, Fienberg A, Hiroi N (2005) DARPP-32 phosphorylation opposes the behavioral effects of nicotine. Biol Psychiatry 58:981-989. 